Research Article

\title{
Simulation Study of the Roof Fracture Pattern of a Horizontal Sublevel Caving in a Steeply Inclined Thick Coal Seam
}

\author{
Xin Kang $\mathbb{D}^{1}{ }^{1}$ Sheng-li Yang, ${ }^{2}$ Ping Zhan, ${ }^{3}$ and Liang-hui Li ${ }^{2}$ \\ ${ }^{1}$ College of Civil Engineering, Tongji University, Shanghai 200092, China \\ ${ }^{2}$ School of Energy and Mining Engineering, Ching University of Mining and Technology-Beijing, Beijing 100083, China \\ ${ }^{3}$ Shanxi Lu'an (mining) Group Co., Ltd., Changzhi 046204, China \\ Correspondence should be addressed to Xin Kang; kangxinwinner@163.com
}

Received 9 December 2019; Accepted 28 March 2020; Published 5 August 2020

Academic Editor: Hui Yao

Copyright (c) 2020 Xin Kang et al. This is an open access article distributed under the Creative Commons Attribution License, which permits unrestricted use, distribution, and reproduction in any medium, provided the original work is properly cited.

\begin{abstract}
Application of a horizontal section top-coal caving in a steeply inclined thick coal seam not only effectively resolves the problem of the large dip angle of the coal seam and slipping and dumping of mining equipment but also significantly reduces the tunnel drivage ratio and improves the extraction yield. In addition, it allows for a safe and efficient mining from a steeply inclined thick coal seam. In this paper, the roof fracture pattern of a steeply inclined thick coal seam has been studied by a similar simulation experiment. The results of the simulation are consistent with those of the numerical calculations, thus verifying the accuracy of the simulation. The experimental simulation results show that the roof can form a step-like toppling failure pattern after drawing the coal, and it is difficult to release a triangular coal mass near the floor, which is the main concentration area of coal loss. The numerical simulation results show that, with the excavation of the coal seam, the rock mass around the goaf produces plastic failure, and the damage is mainly concentrated in the roof area. The upper part of the goaf mainly shows a tensile failure, while the other areas mainly show yield failure.
\end{abstract}

\section{Introduction}

A steeply inclined coal seam refers to a coal seam that has an inclination angle between $45^{\circ}$ and $90^{\circ}$. Such a large angle arises due to a series of complex geological structures, such as folds or faults, which have been formed by violent crustal movements over a long period of time. Although the overall proportion of coal seams in such conditions is small, moving toward west will be the focus of coal resource development in our country for quite a long time to come as the coal reserves in eastern China are running out and coal mining in central China has led to environmental degradation. Due to the special geological conditions in western China, more and more mines will inevitably face the problem of mining steeply inclined thick coal seams. Thus, it is of great significance for rational development and utilization of resources to study the mining methods of coal seams under this condition.
For steeply inclined thick coal seams having thickness above $10 \mathrm{~m}$, the horizontal sublevel caving method has significant advantages: it not only greatly reduces the tunneling rate but also improves the production and benefits. It is more suitable than other methods and should be adopted whenever possible [1]. However, the method will repeatedly disturb the overlying strata and goaf, aggravating their damage, seriously threatening the safety of underground laborers, and making it increasingly difficult to ensure safe mining. In addition, because of the large dip angle of the coal seam and a large concentration of closely located mining sites, the method will aggravate surface movement and deformation, and surface subsidence will become severe. Moreover, water bodies, railways, and other structures located on the surface will be seriously damaged due to the impact of subsidence areas.

Scholars from the country and abroad have done a lot of research in this field. Toke proposed the cantilever beam 
hypothesis in 1916, in which, as a continuous medium, the roof layer above the working face and goaf could be regarded as a beam with one end fixed in the rock mass and the other end in the overhanging state. Qian Minggao [2] put forward a mechanical model of "masonry beam," which provides a theoretical basis for controlling the pressure in the stope and the design of the support. Song Zhenqi put forward the hypothesis of "transfer rock beam," according to which, only a part of the force, generated during the movement of the rocking beam, acts on the support and the force is determined by the control requirements of its movement. Jiachen et al. $[3,4]$ have done a lot of work on the roof fracture pattern of steeply inclined thick coal seams and put forward the "toppling-slumping" failure mode. Yang et al. [5] have also done a lot of work in this regard, believing that the sliding phenomenon will occur on the floor and the downward displacement will increase after the failure of overburden, which will impact the top coal and residual waste rock in the goaf.

After studying the roof structure of a fully mechanized caving face, $\mathrm{Wu}$ [6]pointed out that the caving characteristics of the top coal and direct roof are such that, for a complicated coal seam structure and a thick layer of top coal, an arch balanced structure, namely, a coal-coal structure, can be formed between the caving top coal in the goaf and the uncaving top coal above the support, which is not easy to be destroyed by humans.

Based on the theory of stress arch shell, Wang et al. [7] put forward an evolutionary discriminant coefficient to determine the evolution characteristics of stress arch shell in the overlying rock. Yin et al. [8] found that the position of the middle and bottom portion of the goaf is the maximum deflection point of the inclined thin plate on four sides, and based on this, they established the mechanical model of the overlying rock deformation for a high-dip coal seam. Using the thin plate theory, Zhang [9]analyzed the stress distribution characteristics and fracture mechanism of the basic roof strata when the roof of a high-dip coal seam caves in.

Zhou et al. [10]further analyzed overlying strata movement under the gob after close multiseam being mined out by means of physical simulation and field measurement methods: with the coal seam under the goaf being mined out, the overlying strata constituted a "block-discrete-block" of the complex main roof structure. In the law of overburden rock fracture, $\mathrm{Hu}[11]$ analyzed the failure characteristics of overlying rock in horizontal sublevel caving mining of steeply inclined extra thick coal seam through similar simulation test and found that the fracture form of overlying rock was "inclined trapezoid"; it is concluded that the overall trend of overburden rock fracture migration in horizontal sublevel caving mining in steep coal seam is that the rock strata move down along the strata and the maximum subsidence value is located in the middle and upper part of the working surface.

A comprehensive analysis of the existing investigations indicates that it is of great significance to further study the roof fracture of a horizontal sublevel fully mechanized caving mining in a steeply inclined thick coal seam for further revealing the disaster mechanism in the case of rock fracture. Based on the previous work, an in-depth study on the roof fracture pattern with the help of a similar simulation experiment and numerical simulation software has been done in the present work.

The main work of this paper is similarity simulation experiment and numerical simulation experiment. In the similar simulation experiment, we designed a new experiment table, which is a great innovation, and it helps to achieve more realistic experimental results; in addition, the similarity ratio was determined by observing and comparing the crushing effects of different stones. In the process of similar simulation experiment, we can see a significant steplike failure section; this is a new research result, which is of great significance to the study of steeply inclined and thick coal seam, and in order to verify the experimental results, numerical simulation experiments were carried out.

\section{Engineering Background}

This paper takes a mine in Qinghai as an engineering background. The field area of the mine is $3.31 \mathrm{~km}^{2}$ having recoverable reserves of 73.0916 million tons. Its designed annual output capacity is $900,000 \mathrm{t}$, and its service life is 58 years. Coal seam $20 \#$ is the main mining coal seam. It spans between $85-110^{\circ}$ from west to east, showing an arc protruding slightly to the north, with an average thickness of $20 \mathrm{~m}$ and an inclination angle of $55^{\circ}$. The $20 \#$ coal seam has mostly bright coal, black, bituminous luster, half dark and half bright. The coal seam grade is weak bond coal, and the coal seam is relatively stable and has a bulk density of $1.33 \mathrm{t} / \mathrm{m}^{3}$. The histogram of coal seam is shown in Figure 1.

The whole mine is divided into two levels and five mining areas and each mining area adopts plate mining. The vertical height of each plate is $50 \mathrm{~m}$ and it is divided into two sections. A similar simulation and numerical simulation can be done to study the roof fracture during mining.

\section{Similar Simulation Experiment}

3.1. Introduction to the Similar Simulation Experiment. A similar simulation experiment is a kind of physical simulation method, based on certain similitude principles used for studying specific engineering geological problems, which is the reproduction of a real physical entity. As per the basic requirement of the similarity principle, it can reflect the spatial space relationship between a geological and an engineering structure, accurately simulate the construction process of rock and soil, grasp the mechanical deformation characteristics of rock and soil media, simulate complex engineering construction processes and the effect of load and temporal effect, etc. well, and accurately reflect the force that can destroy the whole process of engineering [12]. Meng et al. [13] carried out an overall similar materials simulation test within a laboratory, contrast to actual measured study of workface with technique parameters selection on fully mechanized top-coal caving in workface 3237 of Zhao Gezhuang coal mine in Kailuan with greater inclined and deep mining situation. This technique's studies have 


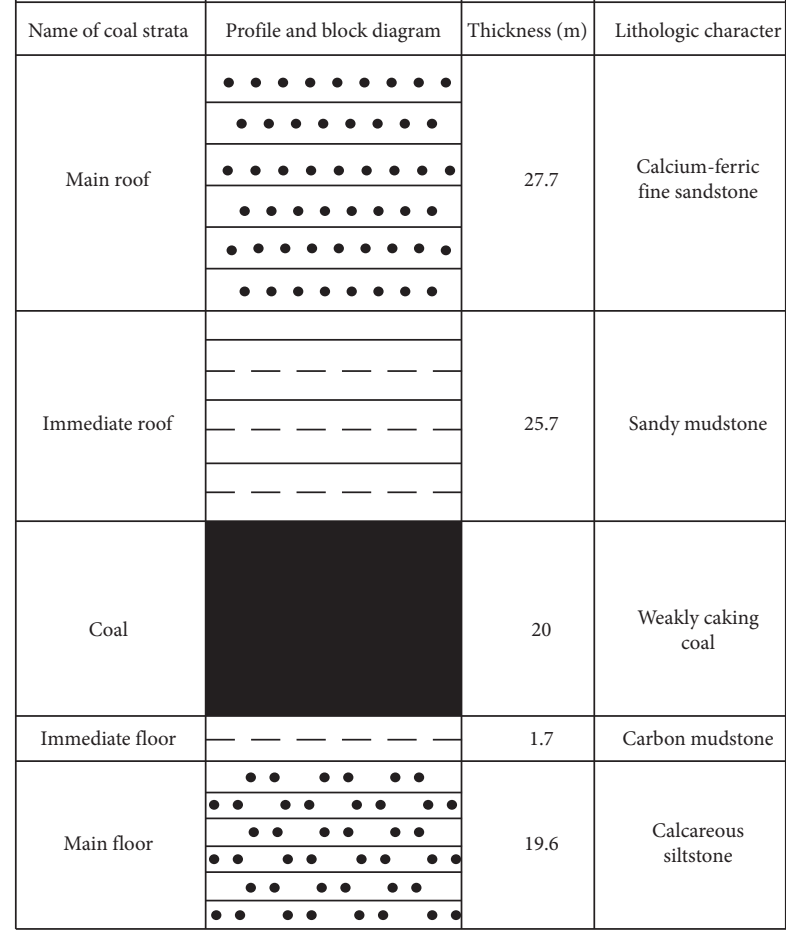

FIgURE 1: The histogram of coal seam.

indicated that it is reliable to prove through practicing in mining of workface and similar materials simulation in laboratory. This method can be used as an important measure of technique parameters selection on fully mechanized top-coal caving.

\subsection{A New Type of Steep Inclination Similar Simulation Table.} The coal seam inclination angle to be simulated is $55^{\circ}$, which is the angle of a steeply inclined coal seam. However, the traditional similar simulation test platform can only simulate near-horizontal coal seams. Thus, in order to achieve realistic experimental results, a new type of steeply inclined similar simulation table with an adjustable angle has been designed for a steeply inclined coal seam. By designing the screw holes of the front and rear baffle into circular arcs, the horizontal laying of the rock layer in the steeply inclined similar simulation experiment, with rotating baffle, can be achieved by tilting the table with a crane. This overcomes the difficulty in simulating a steeply inclined coal seam in the traditional similar simulation table. The three-dimensional drawing of the experiment table is shown in Figure 2.

The main part of the table includes lifting equipment, support, and baffle. When used, the base is first hooked on both sides of the support with two steel cable lines used for lifting equipment and is then raised from the left-hand side to make the overall inclination angle of the support be the same as the coal seam inclination angle to be simulated. The steel cable line hooked onto the base on the right-hand side ensures that the support does not lose balance due to

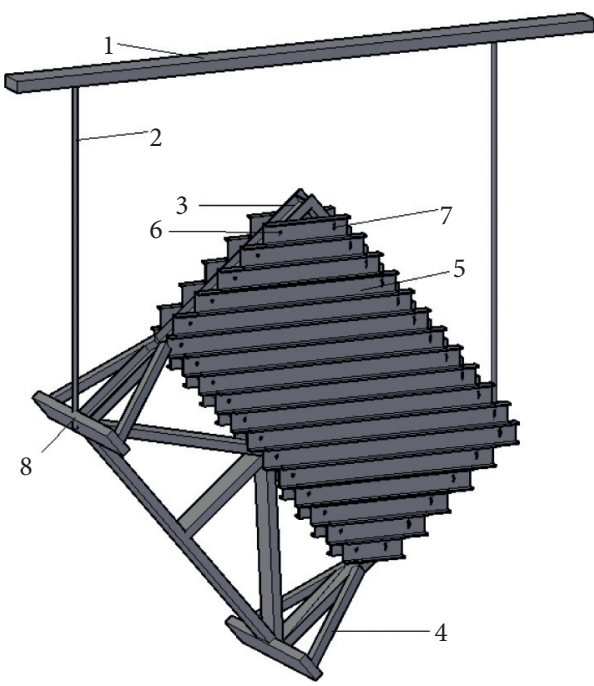

Figure 2: Three-dimensional effect drawing of a new type of similarity simulation experiment table.

unstable center of gravity. At this point, similar materials can be laid horizontally on the inclined table, while the baffles are used to surround the laid materials to prevent collapse.

3.3. Mixing of Similar Materials. The top coal exists in block form before entering the upper part of the support and thus should be in a continuous state when selecting similar materials. Only in this way, it can be consistent with the actual situation and using which accurate scientific conclusions can be obtained. Therefore, in order to better simulate the law of movement of the overburden as the working face advances, $5-8 \mathrm{~mm}$ blue stone particles and sand as an aggregate, lime as a regulator, and water as a cementing agent were used in this experiment and mixed according to a certain ratio. Some selected similar materials are shown in Figure 3.

In order to determine the appropriate ratio of the materials used, it is necessary to conduct a mixing experiment of small test blocks. The matching mold, shown in Figure 4, has dimensions of $10 \mathrm{~cm} \times 10 \mathrm{~cm} \times 10 \mathrm{~cm}$. The material density is $1.72 \times 10^{3} \mathrm{~kg} / \mathrm{cm}^{3}$ and, hence, the mass when the mold is filled is $1.72 \mathrm{~kg}$. Specific ratio parameters are shown in Table 1.

The 9 test blocks made by using the parameters given in Table 2 are shown in Figure 5. As shown on the left-hand side in the figure, they are first placed in the mold for a certain period of time in order to fix their shapes and then taken out of the mold. As shown on the right-hand side in the figure, they are dried in the laboratory for a period of time to make them reach a certain strength for the following force analysis.

In order to intuitively understand the strength of the test block, a free-falling experiment was conducted to let the test block fall at the same height. The fragmentation of the test block was observed and the observations are summarized as shown in Figure 6. 

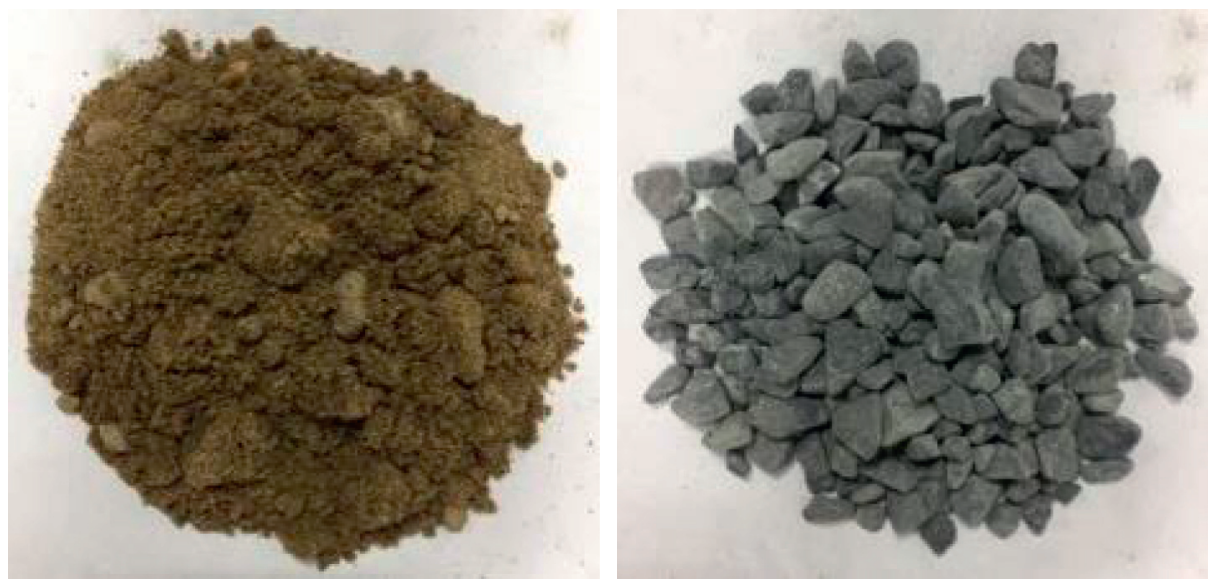

FIgURE 3: Similar material particle.

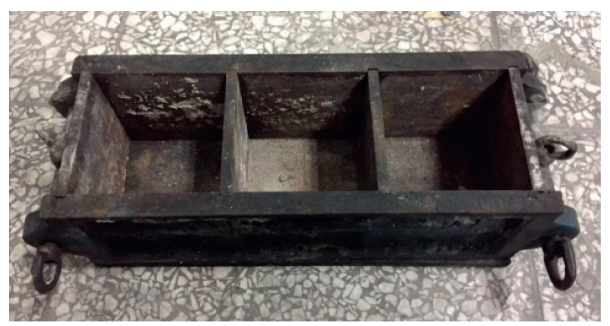

Figure 4: The mold for proportioning experiment.

TABle 1: Physical and mechanical parameters of coal and rock mass.

\begin{tabular}{|c|c|c|c|c|c|c|}
\hline Rock & Body force $\gamma\left(\mathrm{kN} / \mathrm{m}^{3}\right)$ & $\begin{array}{c}\text { Elasticity } \\
\text { modulus E (GPa) }\end{array}$ & $\begin{array}{l}\text { Poisson's } \\
\text { ratio v }\end{array}$ & Tensile strength $(\mathrm{MPa})$ & Cohesion (MPa) & $\begin{array}{c}\text { Internal friction } \\
\text { angle }\left({ }^{\circ}\right)\end{array}$ \\
\hline Fine sandstone & 28.7 & 33.4 & 0.235 & 1.29 & 3.2 & 42 \\
\hline Mudstone & 24.8 & 17.7 & 0.204 & 0.58 & 1.2 & 33 \\
\hline Coal & 13.3 & 5.3 & 0.32 & 0.15 & 1.25 & 32 \\
\hline Mudstone & 24.8 & 17.7 & 0.204 & 0.58 & 1.2 & 33 \\
\hline Siltstone & 24.6 & 19.5 & 0.2 & 1.84 & 2.75 & 38 \\
\hline
\end{tabular}

TABLE 2: The first test block matching experiment.

\begin{tabular}{|c|c|c|c|c|c|c|}
\hline (Sand + gravel): lime: gypsum & Sand : gravel & Sand (kg) & Gravel (kg) & Lime $(\mathrm{kg})$ & Gypsum (kg) & Water $(\mathrm{ml})$ \\
\hline \multirow{3}{*}{$5: 0.5: 0.5$} & $1: 1$ & 0.72 & 0.72 & 0.14 & 0.14 & 120 \\
\hline & $1: 2$ & 0.48 & 0.96 & 0.14 & 0.14 & 103 \\
\hline & $1: 3$ & 0.36 & 1.08 & 0.14 & 0.14 & 86 \\
\hline \multirow{3}{*}{$6: 0.5: 0.5$} & $1: 1$ & 0.74 & 0.74 & 0.12 & 0.12 & 120 \\
\hline & $1: 2$ & 0.49 & 0.98 & 0.12 & 0.12 & 103 \\
\hline & $1: 3$ & 0.37 & 1.1 & 0.12 & 0.12 & 86 \\
\hline \multirow{3}{*}{$7: 0.5: 0.5$} & $1: 1$ & 0.75 & 0.75 & 0.1 & 0.1 & 120 \\
\hline & $1: 2$ & 0.5 & 1 & 0.1 & 0.1 & 103 \\
\hline & $1: 3$ & 0.38 & 1.14 & 0.1 & 0.1 & 86 \\
\hline
\end{tabular}

The following can be observed from the free-fall test:

(1) When sand: gravel = $1: 1$, the test block is not easy to break due to the excessive content of sand

(2) When sand: gravel $=1: 3$, although a large quantity of gravel has been added, the test block is stable and easy to break
(3) When the material similarity ratio is $5: 0.5: 0.5$ ((sand + gravel): lime: gypsum), too high regulator content leads to a high bond strength of the test block, and thus, it cannot be broken easily

(4) When the material similarity ratio is $7: 0.5: 0.5$, reducing the regulator content properly can make the block break fully 

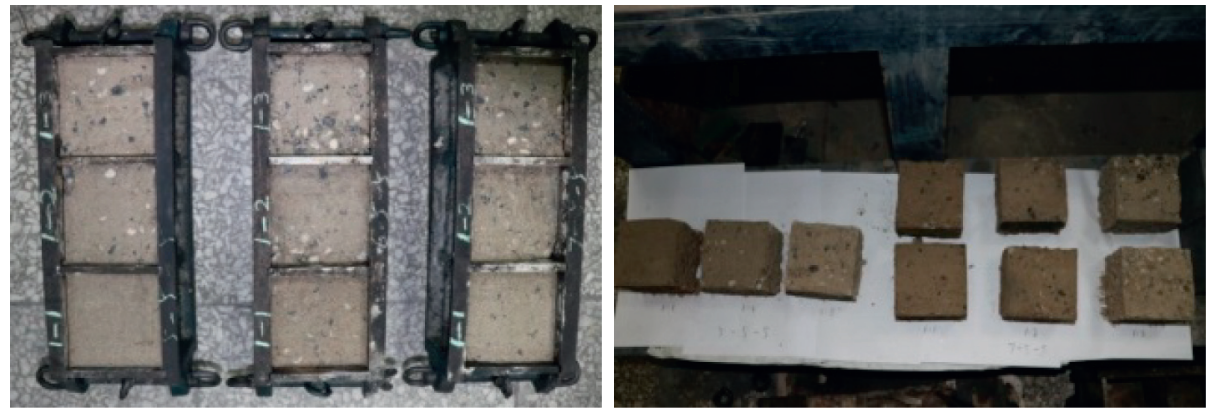

Figure 5: Test block of different proportions.
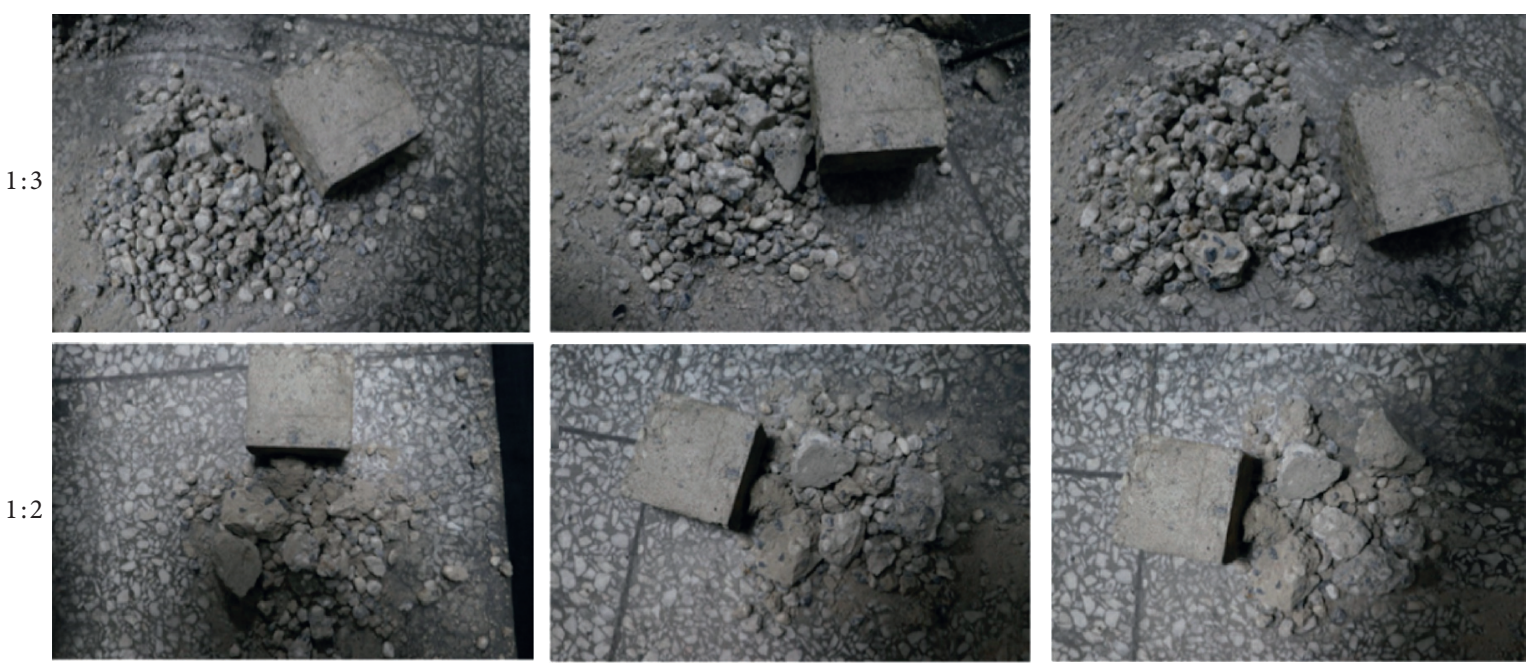

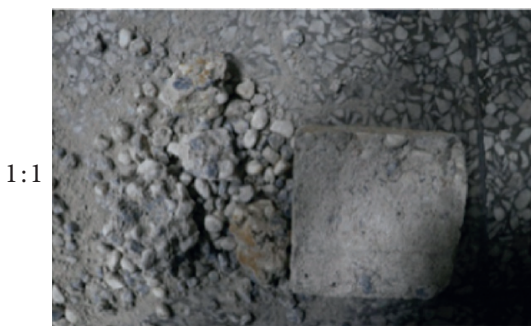

$7: 0.5: 05$

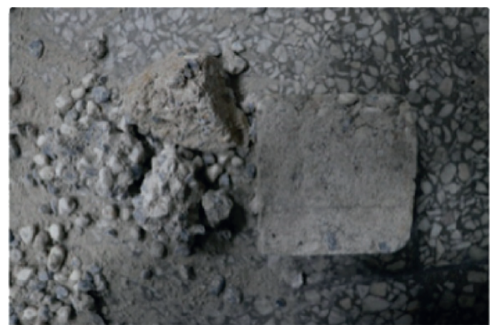

$6: 0.5: 05$

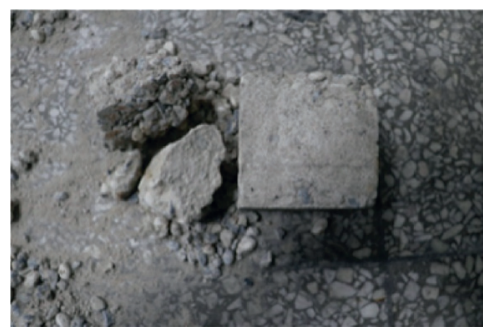

$5: 0.5: 05$

Figure 6: Free-falling experiment.

To sum up, in order to ensure that the similar simulation materials can reach a stable state and break sufficiently after laying, the similarity ratio chosen is (sand + gravel): lime: gypsum $=7: 0.5: 0.5$, where sand: gravel $=1: 3$.

3.4. Experimental Design. According to the actual geological data of the working face, it is known that the vertical height of each plate is $50 \mathrm{~m}$ and is divided into two sections. Each section has a height of $25 \mathrm{~m}$, out of which, the machine mining height is $2.8 \mathrm{~m}$ while the top-coal caving height is $22.2 \mathrm{~m}$. The mining and caving ratio is close to $1: 8$. The average length of the working face is $17 \mathrm{~m}$, and the dip angle of the coal seam is $55^{\circ}$.

The width of the table is $1.8 \mathrm{~m}$, and the overall height is $1.4 \mathrm{~m}$. In order to present the complete mining condition of the two sections, the geometric similarity ratio is set as $\alpha_{\mathrm{L}}=40: 1$. According to the geometric similarity ratio, the coal seam area has a thickness of $50 \mathrm{~cm}$. Sand, lime, and gypsum were used for mixing on both sides of the roof and floor as per the ratio mentioned above and the pressure from the overburden was simulated by placing heavy blocks. The overall effect after the experimental model is constructed is shown in Figure 7. In order to simulate the coal drawing process, 11 wooden boards with a thickness of $7 \mathrm{~cm}$ were selected to simulate supports (numbered 1-11 from right to left in Figure 7). Multiple rounds, intervals, and sequences of coal drawing from the floor of the coal seam to the roof have been adopted to discharge coal. The upper section is mined first followed by the lower section.

3.5. Analysis of the Experimental Simulation. After the strength of the experimental material reached its predetermined value, excavation was carried out to draw coal. 


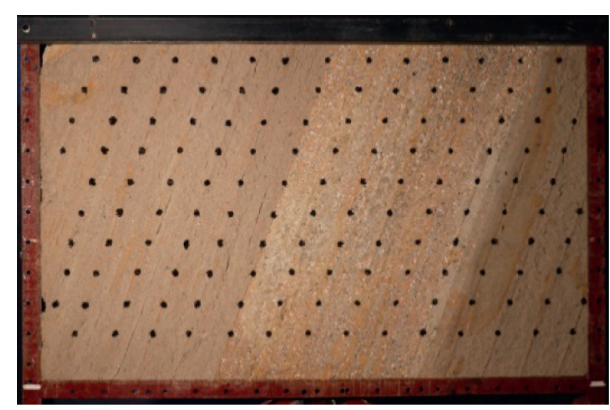

FIgURE 7: Sketch map of model laying.

In the first round of coal drawing from the upper section, a small amount of coal was released, the roof was relatively complete, and the displacement was basically unchanged, as shown in Figure 8(a). The upper support (No. 4) holding the top layer of coal served as a separation layer and the collapsed roof mixed into the coal body to form the circular coal and rock interface. The whole process of releasing the top layer of coal is close to the roof side and there is still a lot of top coal on the floor side. During the second round of coal drawing, the upper part of the roof caved and deformed and the roof subsidence was obvious. Support No. 11 basically released the triangular residual coal near the roof side, and the roof showed a rotary fracture, presenting a step-like failure pattern. At the same time, two coal and rock interfaces were formed in the middle of the working face and near the roof side, as shown in Figure 8(b).

After the first round of coal drawing in the upper section, the damage of the roof is observed to be similar to that of the upper section, and the displacement is small as compared to the upper section. The top-coal output is less and the roof stability is better, as shown in Figure 9(a). In the second round, when coal is drawn from the region around support No. 5, the upper part of the roof appears to be partially damaged. The whole top coal shows a downward trend and part of the top coal is connected between the roof and the floor in an arch. With the drawing coal from around support No. 11, the roof appears to show a toppling failure and the subsidence of the roof increases sharply. After the coal drawing, a significant step-like failure section appears, as shown in Figure 9(b).

\section{Verifying the Results of the Similar Simulation Experiment}

The results of a similar simulation experiment have been verified using numerical analysis software.

\subsection{Building the Universal Distinct Element Code (UDEC)} Model. The length of the designed model is $100 \mathrm{~m}$, the height is $90 \mathrm{~m}$, and there are 25816 blocks in total. The vertical stress is $5.4 \mathrm{MPa}$ for a depth of $200 \mathrm{~m}$, and the horizontal stress is 1.5 times the vertical stress value. The two sides of the boundary are characterized by the velocity boundary conditions, and the velocity in $x$-direction is zero, it is simple support, while the bottom boundary condition is the solid support and the velocity in $x$ and $y$ direction is zero. The numerical calculation model is shown in Figure 10.

4.2. Determining the Parameters. The Mohr-Coulomb constitutive model has been adopted for the numerical calculations. Different properties of each rock layer are endowed by a series of rock mechanics experiments combined with the column diagram of the coal seam, as shown in Table 1.

4.3. Analysis of the Simulation Results. The overburden movement rule after stoping is shown in the figure above. It can be seen from Figure 11(a) that the coal above the goaf will bend and sink to a certain extent after the end of stoping. It can be clearly seen from Figure 11(b) that both the lower and the middle parts of the roof above the coal seam have step-like failure patterns, which is similar to the results of the similar simulation. This verifies the step-like patterns that occur when the roof toppling fails. As can be seen from the diagram showing the development of a plastic zone, as shown in Figure 11(c), a large area of failure unit appears in the surrounding rock of the coal seam excavation, and the area where tensile failure occurs is concentrated in the coal body above the goaf.

4.4. Building the Fast Lagrangian Analysis of Continua in 3Dimensions (FLAC3D) Model. The length of the designed model is $72 \mathrm{~m}$, the height is $90 \mathrm{~m}$, and the width is $150 \mathrm{~m}$. The model is divided into 618,150 hexahedral elements and generates 637,792 mesh nodes. The $X$-axis is parallel to the direction of the working face layout, the $Y$-axis is parallel to the working face advancement direction, and the $Z$-axis is in the vertical direction. The Mohr-Coulomb constitutive model has been adopted for the calculations. Horizontal displacement is limited to the left and right sides in the horizontal direction, in the model, and horizontal and vertical displacement has been limited to the bottom portion of the model. The gravity stress of the overburden has been applied at the top of the model. The established numerical model is shown in Figure 12.

4.5. Determining the Parameters. Based on the rock mechanics test results provided by the field geological survey and related studies and considering the effect of the rock size, the physical and mechanical parameters of coal and rock mass used in the numerical model are shown in Table 3.

4.6. Analysis of Simulation Results. The scope of failure of the surrounding rock mass except the upper coal body continues to extend outwards with the advance of the work surface, as shown in Figure 13. With the advance of the lower section, especially between $50 \mathrm{~m}$ and $100 \mathrm{~m}$, the failure area of the roof increases sharply and extends to the far left in the model. Most areas of the top coal body and floor do not extend outward, but the floor near the top coal body shows 


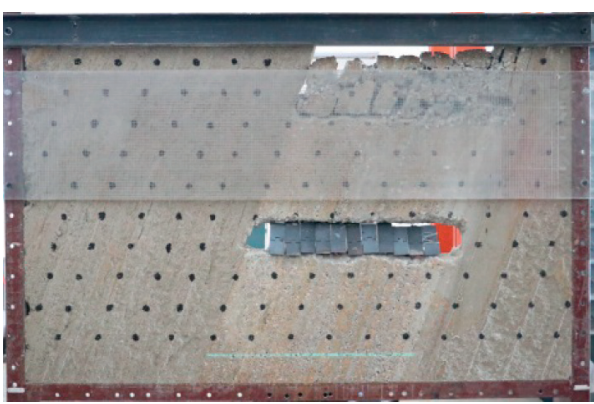

(a)

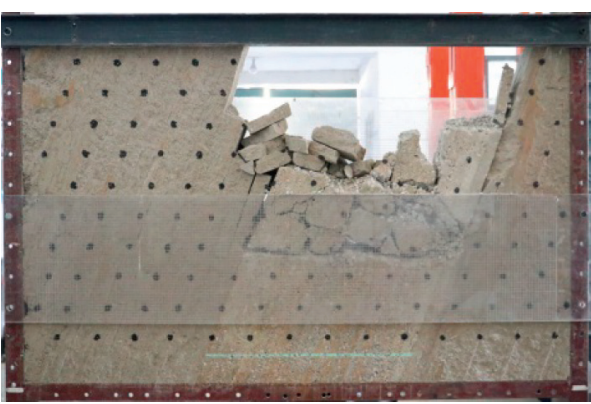

(b)

Figure 8: Upper section coal drawing process. (a) Before upper section coal drawing. (b) After upper section coal drawing.

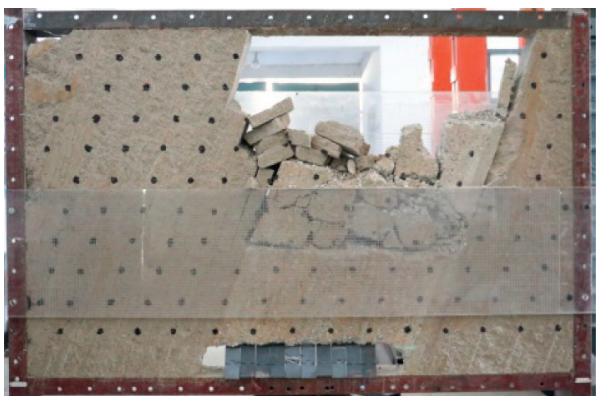

(a)

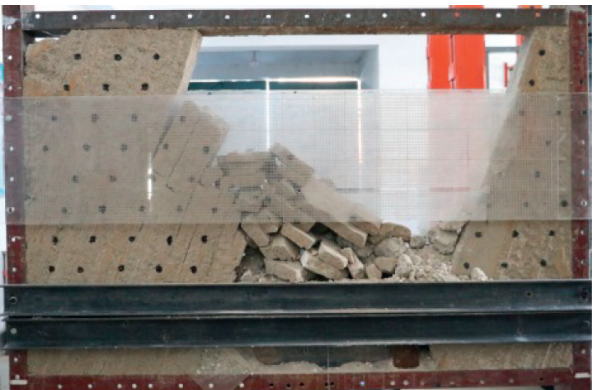

(b)

FIgURE 9: Lower section coal drawing process. (a) Before lower section coal drawing. (b) After lower section coal drawing.

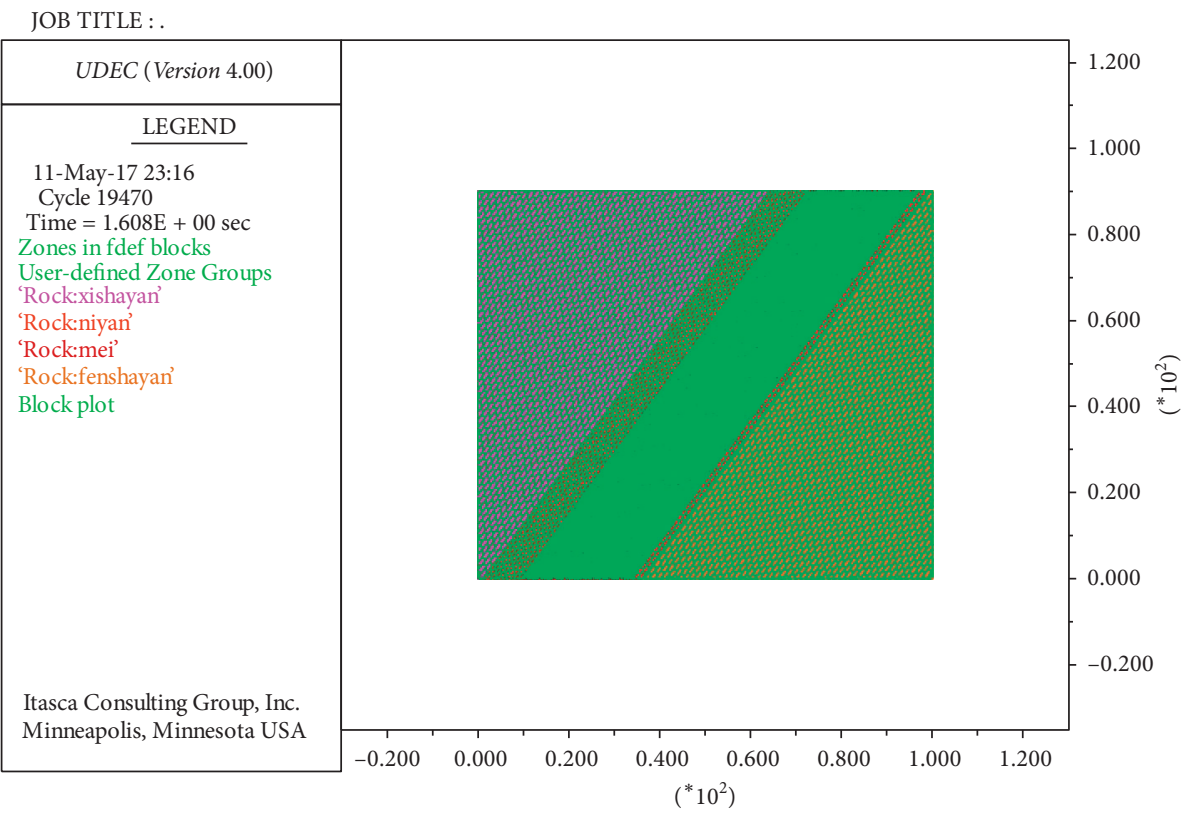

Figure 10: Numerical calculation model. 


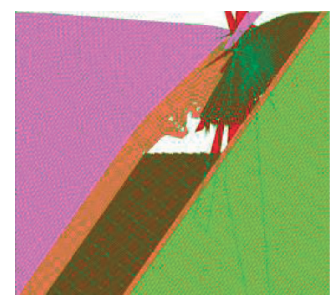

Block plot

No. zones : total 20894

At yield surface $(*) 709$

Yielded in past (X) 5469

Tensile failure (o) 512

(a)

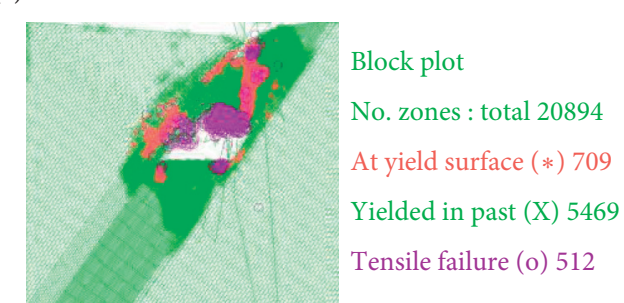

(c)

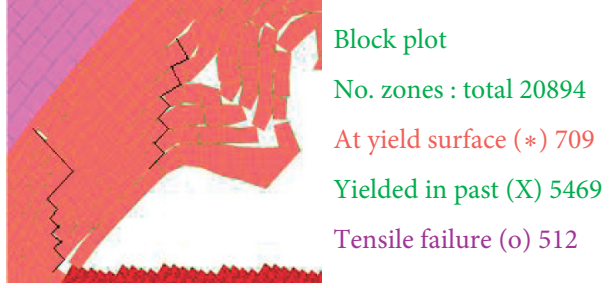

(b)

Figure 11: Overburden movement rule. (a) Diagram of overburden movement. (b) Step-like failure pattern. (c) The plastic zone figure.

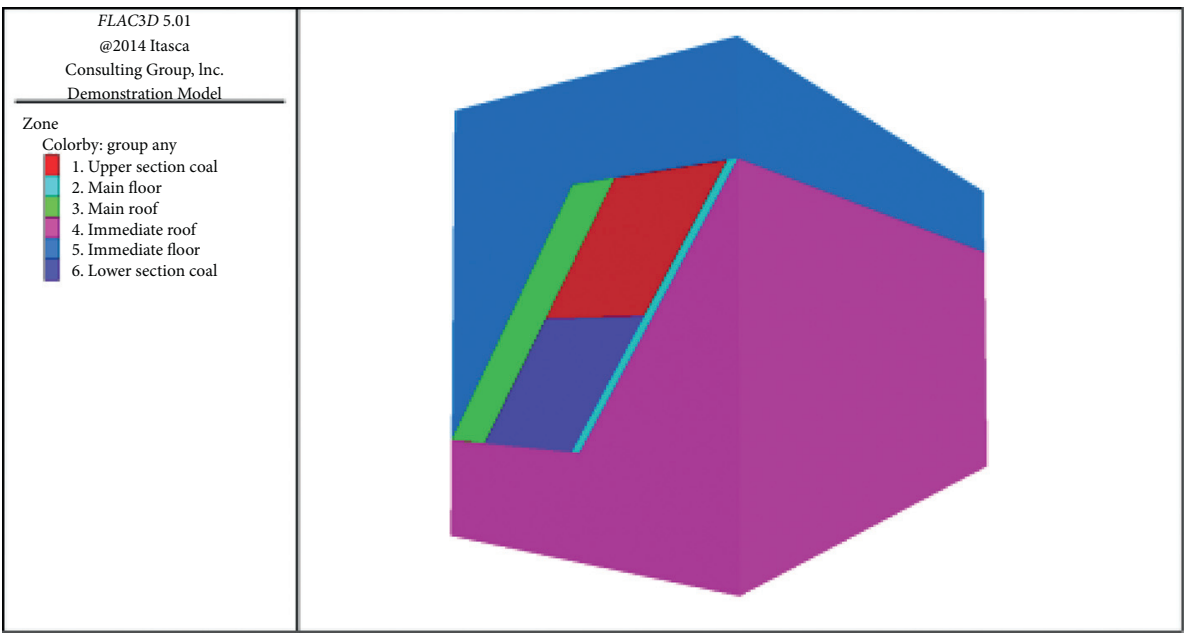

FiguRE 12: Numerical calculation model.

TABle 3: Physical and mechanical parameters of coal and rock mass.

\begin{tabular}{|c|c|c|c|c|c|c|}
\hline Rock & $\begin{array}{l}\text { Body force } \gamma \\
\left(\mathrm{kN} / \mathrm{m}^{3}\right)\end{array}$ & $\begin{array}{c}\text { Elasticity modulus E } \\
(\mathrm{GPa})\end{array}$ & Poisson's ratio v & $\begin{array}{c}\text { Tensile strength } \\
(\mathrm{MPa})\end{array}$ & $\begin{array}{c}\text { Cohesion } \\
(\mathrm{MPa})\end{array}$ & Friction angle $\left({ }^{\circ}\right)$ \\
\hline Main roof & 28.7 & 33.4 & 0.235 & 1.29 & 3.2 & 42 \\
\hline Immediate roof & 24.8 & 17.7 & 0.204 & 0.58 & 1.2 & 33 \\
\hline Coal & 13.3 & 5.3 & 0.32 & 0.15 & 1.25 & 32 \\
\hline Immediate floor & 24.8 & 17.7 & 0.204 & 0.58 & 1.2 & 33 \\
\hline Main floor & 24.6 & 19.5 & 0.2 & 1.84 & 2.75 & 38 \\
\hline
\end{tabular}




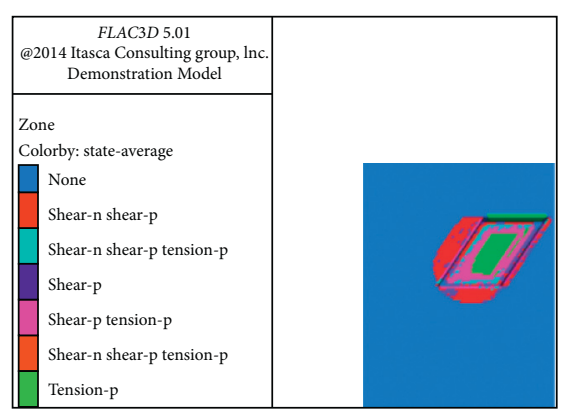

(a)

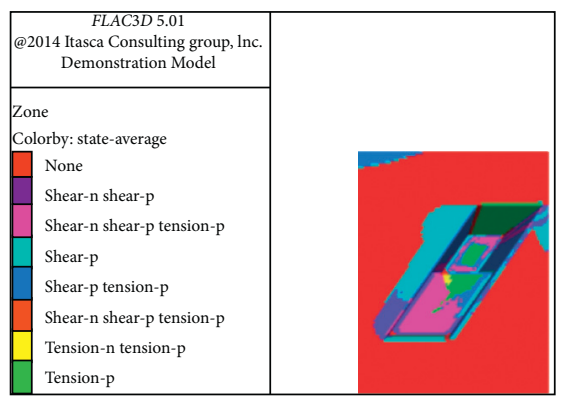

(d)

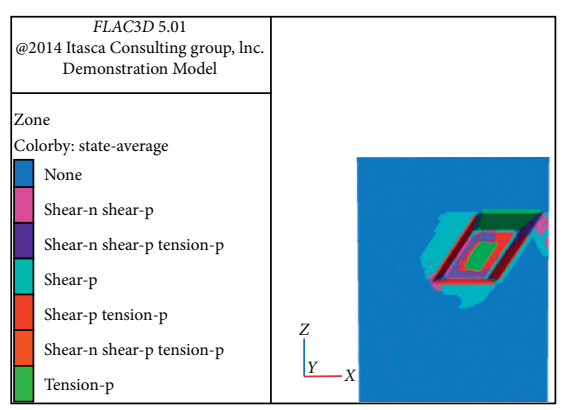

(b)

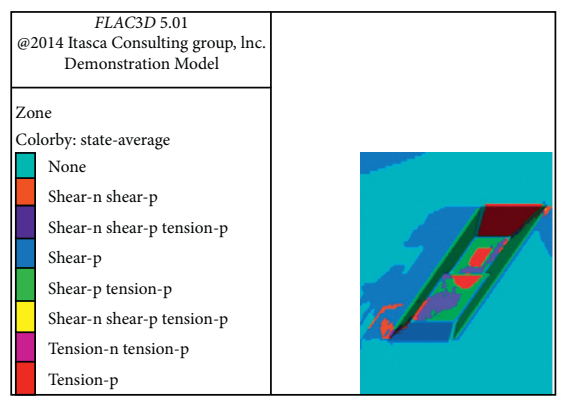

(e)

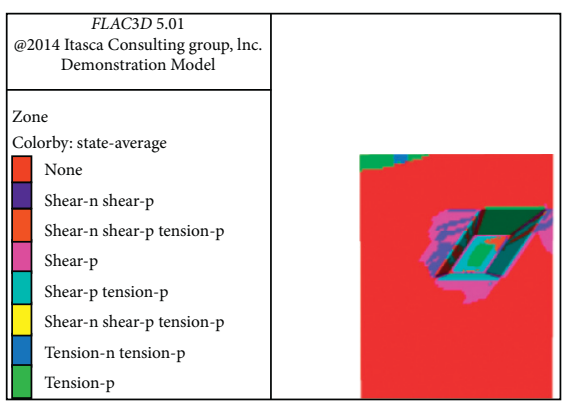

(c)

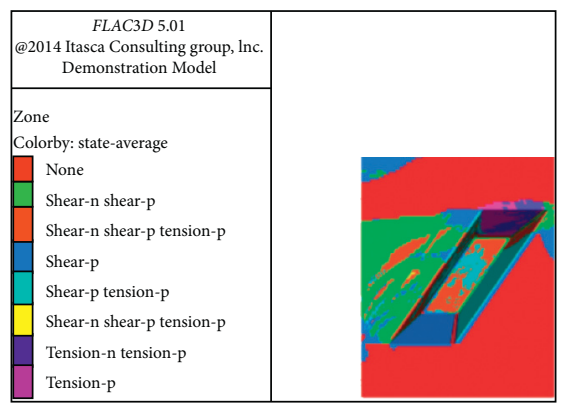

(f)

Figure 13: Rock's plastic zone distribution. (a) The upper section advances $10 \mathrm{~m}$. (b) The upper section advances $50 \mathrm{~m}$. (c) The upper section advances $100 \mathrm{~m}$. (d) The lower section advances $10 \mathrm{~m}$. (e) The lower section advances $50 \mathrm{~m}$. (f) The lower section advances $100 \mathrm{~m}$.

an obvious shear failure. It can be seen from the simulation results that the floor slippage is easy to occur here.

\section{Conclusions}

(1) In the process of horizontal section top-coal caving in a steeply inclined thick coal seam, the roof can exhibit a step-like toppling failure pattern. With the gradual downward extension of the mining sections and the progress of the coal drawing process, it is difficult to release triangular coal mass near the floor, which is the main concentration area of coal loss.

(2) UDEC numerical simulation results show that, with the excavation of the coal seam, the rock mass around the goaf produces plastic failure, and the damage is mainly concentrated in the roof area. The upper part of the goaf mainly shows a tensile failure, while the other areas mainly show yield failure.

(3) FLAC $^{3 \mathrm{D}}$ numerical simulation results show the displacement subsidence is increasing while the bulge decreases. The horizontal displacement is increasing and after stoping it is much larger than the vertical displacement. The roof gets displaced mainly in the horizontal direction, and the displacement in the early stage is also larger than the vertical displacement when the rock block is toppled.

\section{Data Availability}

No data were used to support this study.

\section{Conflicts of Interest}

The authors declare that they have no conflicts of interest.

\section{Acknowledgments}

The authors are also pleased to acknowledge Mr. Yan Baojin for his guidance to the experiments. This paper was supported by the National Natural Science Foundation of China (Grant no. 51974320).

\section{References}

[1] J. Du and X. Meng, Mining Engineering, China university of mining and technology press, Xuzhou, China, 2009.

[2] M. Qian, P. Shi, and J. Xu, Mining Pressure and Strata Control, China university of mining and technology press, Xuzhou, China, 2001.

[3] W. Jiachen, Z. Bingwen, Z. Pengfei et al., "Research on the longwall top-coal caving mining technique in extremely inclined and soft thick coal seam," Journal of China Coal Society, vol. 42, no. 2, pp. 286-292, 2017.

[4] J. Wang, S. Yang, and L. Li, “Toppling-slumping failure mode in horizontal sublevel top-coal caving face in steeply-inclined seam," Journal of China University of Mining \& Technology, vol. 47, no. 6, pp. 1175-1184, 2018.

[5] S. Yang, B. Zhao, and Yi Yang, "Experimental study on failure mode of horizontal sublevel caving in steeply inclined thick coal seam," Coal Engineering, vol. 49, no. 10, pp. 7-11, 2017.

[6] S. Wu, S. Yang, and C. Lai, "Research on roof structure of fully mechanized caving face," Journal of Coal Science and Technology, vol. 27, no. 2, pp. 39-41, 1999.

[7] H. Wang, Y. Wu, and P. Xie, "Formation and evolution characteristics of rock stress field in steeply dipping seam 
mining," Journal of Lliaoning Technical University (Natural Science), vol. 32, no. 8, pp. 1022-1026, 2013.

[8] G. Yin, D. Wang, and W. Zhang, "Mechanical model and application of overburden deformation in deep mining of steeply inclined coal seam," Journal of Chongqing University (Natural Science Edition), vol. 29, no. 2, pp. 79-82, 2006.

[9] Y. Zhang, J. Cheng, X. Wang et al., "Thin plate model analysis on roof break of up-dip or down-dip mining stope," Journal of Mining \& Safety Engineering, vol. 27, no. 4, pp. 487-493, 2010.

[10] N. Zhou, Q. Zhang, B. An, and S. Nie, "Strata behavior below the gobs of close upper seams [J]," China Coal, vol. 37, no. 2, pp. 48-51+96, 2011.

[11] H. Hu, "Failure characteristics of overburden rock in horizontal sublevel fully mechanized caving in steeply inclined extra-thick coal seam," Inner Mongolia Coal Economy, no. 11, pp. 104-119, 2015.

[12] Q. Zhang, S. Li, and Y. Li, New Method, New Technology and Engineering Application of Underground Engineering Model Test, Science Press, Beijing, China, 2012.

[13] X. Meng, Y. Zhang, L. Chaohui, Z. Li, and Y. Guo, "Study of technique simulating test on fully mechanized top-coal caving work face in greater inclined and thick coal seams," China Mining Magazine, vol. 18, no. 3, pp. 72-76, 2009. 